\title{
Development of Reverse Transcriptase PCR and Nested PCR to Detect Porcine Hemagglutinating Encephalomyelitis Virus
}

\author{
Yoshiko SEKIGUCHI ${ }^{1)}$, Junsuke SHIRAI ${ }^{2)}$, Takahide TANIGUCHI ${ }^{1)}$ and Eiichi HONDA ${ }^{1)}$ \\ ${ }^{1)}$ Department of Veterinary Microbiology, Tokyo University of Agriculture and Technology, 3-5-8 Saiwai-cho, Fuchu, Tokyo $183-8509$ \\ and ${ }^{2)}$ Department of Exotic Diseases Research, National Institute of Animal Health, 6-20-1 Jyosui-honcho, Kodaira, Tokyo 187-0022, \\ Japan
}

(Received 28 July 2003/Accepted 3 December 2003)

\begin{abstract}
Porcine hemagglutinating encephalomyelitis virus (HEV) causes encephalomyelitis, or vomiting and wasting disease, in suckling piglets. The mortality rate for piglets under 3 weeks old is $100 \%$, but they are usually protected by maternal antibodies. Recently, the risk of an HEV outbreak has increased in the pig industry, because of widely using specific pathogen-free pigs that have noantibodies to HEV. We developed reverse transcription (RT) PCR and nested PCR to detect HEV. Primer sets of polymerase, non-structural protein, and spike protein were designed for RT-PCR and nested PCR based on the nucleotide sequences of the HEV 67N strain. The PC R designated primer sets of spike protein detected only HEV viral RNA among other related nidoviruses. Detection of HEV viral RNA by nested PCR was more sensitive than virus isolation in cell cultures. Nested PCR detected HEV viral RNA from experimentally infected samples of mice and field samples of piglets. The RT-PCR and nested PCR methods to detect HEV is considered a good way to show the HEV etiology on pig farms.
\end{abstract}

KEY WORDS: HEV, nested PCR, RT-PCR.

J. Vet. Med. Sci. 66(4): 367-372, 2004

Porcine hemagglutinating encephalomyelitis virus (HEV) is a member of the genus Coronavirus, family Coronaviridae, order Nidovirales [3]. HEV causes encephalomyelitis, or vomiting and wasting disease in suckling piglets. Pigs are the only species naturally susceptible to $\mathrm{HEV}$; mice and rats can be experimentally infected with HEV. When piglets under 3 weeks old are infected with $\mathrm{HEV}$, their mortality rate is $100 \%$, but pigs more than 3 weeks show no obvious clinical signs [20].

HEV was first isolated in 1962 in Canada from suckling piglets with encephalomyelitis, and since then the virus has been found worldwide [18]. In 1973, a hemagglutinating inhibition test to detect the antibodies to HEV showed that approximately $50 \%$ of pigs had HEV antibodies in Japan [7]. In 1984, HEV was isolated from the respiratory tracts of 3-month-old pigs with respiratory symptoms in Japan [6], but Japan has had no marked outbreaks of HEV. In an etiological survey of HEV, many neonatal piglets received maternal antibodies to HEV from the colostrum of sows that protect against HEV. Pigs have an age-related resistance to HEV [20].

Recently, production of specific pathogen-free (SPF) pigs has been popular in pig farms in Japan. Primary SPF pigs are produced by Caesarean operation but are sterile, have no colostrum, and so they have no maternal antibodies [1]. Therefore, secondary SPF pigs, the offspring of primary SPF pigs, have no protective antibodies to diseases such as $\mathrm{HEV}$, which are usually protected against by maternal antibodies in non-SPF pigs. If the pigs are already infected with $\mathrm{HEV}$, controlling HEV in primary or secondary SPF pigs is difficult. If an HEV outbreak occurred in SPF pigs, enormous economic loss would be the result because of the high mortality of neonatal piglets under 3 weeks old. In January
2001 in Japan, 200 piglets died because they were born from sows introduced on to a farm and they showed HEV-like symptoms (unpublished data). Therefore, we considered that investigating the etiology of HEV pathogenically is important, because HEV may cause outbreaks. In this study, we developed rapid and sensitive methods to detect HEV by RT-PCR and nested PCR.

\section{MATERIALS AND METHODS}

Viruses: HEV 67N strain (18) and ONS204 strain (6), coronaviruses of bovine coronavirus (BCV) Mebus strain [17], mouse hepatitis virus (MHV) JHM strain [16], transmissible gastroenteritis virus (TGEV) h5 strain [12], and the arterivirus porcine reproductive and respiratory syndrome virus (PRRSV) EDRD strain [19] were used.

Cells: The swine kidney cell line FS-L3 [21] was used for HEV preparation and isolation. Cells were grown and maintained in a serum- free medium (MEM containing $0.2135 \% \mathrm{~N}, \mathrm{~N}-\mathrm{Bis}-$ amino-ethanesulfonic acid, $0.45 \%$ Bactopepton, $0.045 \% \mathrm{~L}$-glutamine, $0.2 \% \mathrm{NaHCO}_{3}$, and $0.295 \% \mathrm{TPB})$. Bovine kidney cell 4 th culture was used for the preparation of BCV [17]. DBT cell was used for the preparation of MHV [16]. CPK cell was used for the preparation of TGEV [12]. MARC145 cell was used for the preparation of PRRSV [19]. All cells except for FS-L3 was grown and maintained in MEM medium containing 5\% fetal bovine serum.

Primers: The design of the primers for RT-PCR and nested PCR of HEV were based on the nucleotide sequences of polymerase genes (Pol) (23; DDBJ: AF124988), nonstructural protein genes (NS) (24; DDBJ: S79187), spike protein genes (S2) (25; DDB : PHEV67N) of the $67 \mathrm{~N}$ strain. 


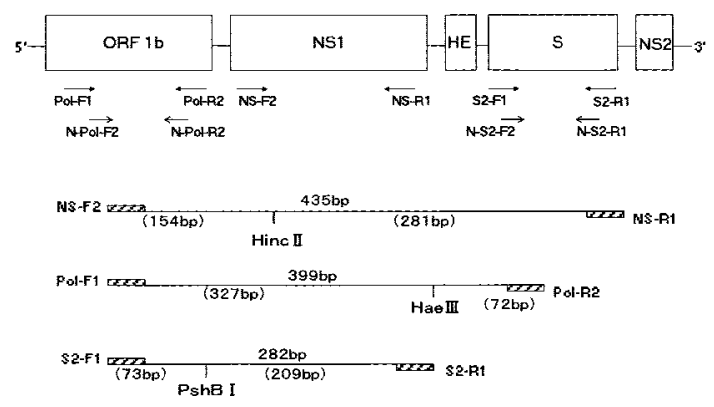

Fig. 1. Schematic representation of the HEV genome and the location of the PCR primers. The predicted sizes of the RT-PCR amplified products, and the restriction enzyme cleavage sites are shown.

First, primer sets that can amplify the $67 \mathrm{~N}$ RNA were designed and were used for RT-PCR as follows:

Pol-F1: 5'-TATACTAAGCGCAATGTCCTGCC-3', Pol-R2 : 5'-GTGCGCATTCATTCGCGAGTCG-3', NS-F2 : 5'-ATGCTTGGTGC CGTAACCAAGG-3', NS-R1: 5'-CGTCATCCACATCAAGGACTGG-3', S2-F1 : 5'-GTTACAGCAAAGGTTAGTCCTGG-3', S2-R1 : 5'-AATCTGGTGCCACTGA AGATTGG -3'.

Then, the primer sets that can amplify inside of the amplification sites of RT-PCR primers were designed and were used for nested PCR as follows:

N-Pol-F2 : 5'-AGTATAGCAGCTACACGTGGCG-3', N-Pol-R2 : 5'-GGGCCAATACCAGACTACTAAC-3', N-S2-F2 : 5'-TGGATGTTCACTGGTAGTAGC-3', N-S2-R1 : 5'-GGTTGGGTGTCGATGTGTTCAGC-3'.

Figure 1 shows the primer locations and sizes of the predicted amplified products. Oligonucleotide primers were used at a concentration of 20 pmol per $\mu l$ for the RT-PCR and nested PCR.

RNA samples: Viral genomic RNA was extracted by using a commercial RNA isolation kit (RNA zol B, TELTEST Inc., Texas, U.S.A.). Fifty $\mu l$ of virus-infected cell culture fluid or $50 \mu \mathrm{l}$ of the supernatant of a $10 \%$ homogenate of tissue were mixed with $1 \mathrm{~m} l$ of the RNA zol B. The mixture was then treated according to the manufacturer's instructions. The final precipitate of RNA was used as template RNA for RT-PCR.

$R T$-PCR: RT-PCR was done as follows. A mixture of 1 $\mu l$ of template RNA, $18.5 \mu l$ of the regent mixture of Titan One Tube RT-PCR kit (Roche Diagnostics Co., Ltd., Tokyo, Japan), $1 \mu l$ each of a forward and a reverse primer, and $26.5 \mu \mathrm{l}$ of RNase-free distilled water were first incubated at $50^{\circ} \mathrm{C}$ for $30 \mathrm{~min}$, and then at $94^{\circ} \mathrm{C}$ for 2 min according to the manufacturer's instructions. Then the mixture was amplified at 25 cycles, each cycle consisting of 30 -sec denaturation, 30-sec annealing, and 45-sec elongation at temperatures of $94^{\circ} \mathrm{C}, 65^{\circ} \mathrm{C}$, and $68^{\circ} \mathrm{C}$ respectively. The PCR ended with a final elongation for $7 \mathrm{~min}$ at $68^{\circ} \mathrm{C}$. The amplified products were detected by electrophoresing $5 \mu l$ of samples through a $2 \%$ agarose gel in Tris-EDTA Acetate
(TAE) buffer.

Nested PCR: Nested PCR was done in $50 \mu l$ of reaction mixture containing $0.1 \mu l$ of RT-PCR product, $2 \mu l$ each of the forward and reverse nested primers, 22.9 $\mu \mathrm{l}$ of distilled water and $25 \mu l$ of reagent mixture of PCR Master (Roche Diagnostics Co. Ltd., Tokyo, Japan). The mixture was amplified at 25 cycles, each cycle consisting of 30-sec denaturation, 30-sec annealing, and 30-sec elongation at temperatures of $94^{\circ} \mathrm{C}, 65^{\circ} \mathrm{C}$, and $72^{\circ} \mathrm{C}$, respectively. The PCR ended with a final elongation at $72^{\circ} \mathrm{C}$ for $7 \mathrm{~min}$. The amplified products were detected by electrophoresing $5 \mu l$ of product through a $2 \%$ agarose gel in TAE buffer.

Restriction enzyme digestion: The RT-PCR amplified product $(5 \mu l)$ purified by means of a QIA quick PCR Purification Kit (QIAGEN K.K., Tokyo, Japan) was mixed with $1 \mu l$ of restriction enzymes Hinc II, Hae III, and PshB I (TAKARA Biomedicals Co., Ltd., Tokyo, Japan) and was incubated at $37^{\circ} \mathrm{C}$ for $1 \mathrm{hr}$. The RT digestion products were analyzed by electrophoresis as described above.

Inoculating HEV into mice: Two-month-old female mice were inoculated intraperitoneally with $0.5 \mathrm{ml}$ of $\mathrm{HEV}$ ONS204 strain $\left(10^{4}\right.$ tissue culture infectious dose (TCID) ${ }_{50} /$ $100 \mu l)$. Blood, brain, liver, kidney and spleen samples were collected from the mice anesthetisized deeply and killed with ether at 3 days and 5 days after inoculation. The collected tissues were homogenated with 10 times the volume of PBS and were centrifuged at 6,000 rpm for $5 \mathrm{~min}$. The supernatants were used for RNA extraction for applying RT- PCR and nested PCR.

Field clinical samples: Thirty-two brain and tonsil homogenates from 19 piglets aged from 1 week to 3 months which showed runting and were humanely killed in the Kanto area of Japan were used for the field clinical samples. RNA was extracted from the homogenates as described in 2.4. RNA samples and was used for RT- PCR and nested PCR.

Virus isolation from clinical samples: One day after cultivation, the FS-L3 cell monolayer of each well of 24-well plastic plates was inoculated with $100 \mu l$ of the clinical samples and was examined every day. The inoculated supernatants were collected on the fifth day and were passaged in a fresh cell cultures grown in 24-well plastic plates and were examined for 5 days. Finally, the samples showing a cytopathic effect were examined by using the indirect fluorescent antibody test for identify HEV.

\section{RESULTS}

Specificity and sensitivity of the PCR: Viral RNA was extracted from HEV 67N and ONS204 strains, MHV JHM strain, BCV Mebus strain, TGEV h5 strain and PRRSV EDRD strain; each extraction was used for RT-PCR. The designed S2 primers only amplified both HEV strains to the predicted size of $282 \mathrm{bp}$.

The $435 \mathrm{bp}, 399 \mathrm{bp}$ and $282 \mathrm{bp}$ amplified products of the RT-PCR were treated with restriction enzymes, Hinc II, Hae III, and $P s h B$ I, respectively, to confirm the presence of the 


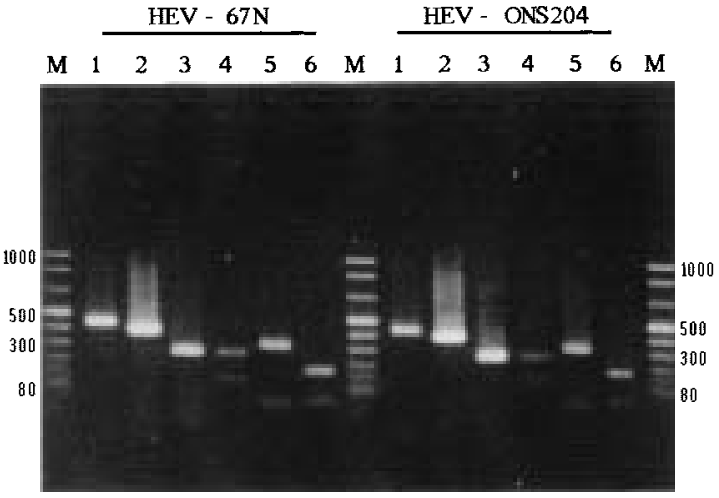

Fig. 2. Digestion of the RT-PCR amplified products with restriction enzymes. 1: NS product, 2: Pol product, 3: S2 product, 4: Hinc II, specific for NS product, 5: Hae III, specific for Pol product, 6: PshB I, specific for S2 product. $\mathrm{M}$ : a molecular weight marker of a $100 \mathrm{bp}$ DNA ladder.

restriction enzyme cleavage sites (Fig. 1). Hinc II cleaved NS products of both $67 \mathrm{~N}$ and ONS204 strains into the predicted sizes of fragments $154 \mathrm{bp}$ and $281 \mathrm{bp}$. Hae III cleaved Pol products of both strains into the predicted sizes of fragments $72 \mathrm{bp}$ and $327 \mathrm{bp}$. PshB I cleaved S2 products of both strains into the predicted sizes of fragments $73 \mathrm{bp}$ and 209 bp (Fig. 2). PCR products were confirmed its specificity by sequencing.

The RT-PCR products were amplified by nested PCR with Pol and S2 primers, and the predicted sizes of the products were detected. The sensitivity of the nested PCR using Pol and S2 primers corresponded to $10^{-2} \mathrm{TCID}_{50} / 50 \mu l$ and $10^{-1} \mathrm{TCID}_{50} / 50 \mu l$, respectively (Fig. 3).

Comparison of the detection of HEV from mice samples by virus isolation and PCR: Amplification of viral RNA in the tissue samples of mice inoculated with HEV intraperitoneally were detected by nested PCR with the Pol primer (Table 1). In mice, humanely killed at 3 days and 5 days after inoculation, the infectious virus was not detected in either sample. Viral RNA was not detected by RT-PCR in either sample. In contrast, by nested PCR, amplification of viral RNA was detected in the kidney, liver and spleen at 3 days after inoculation, and in the brain, kidney and spleen at 5 days after inoculation. HEV viral RNA was not detected in blood samples.

Comparison of the detection of HEV from field clinical samples: The epidemiological data of the field samples and the results are shown in Table 2. No. 1-2 piglets aged 1-2 weeks were diagnosed with Aujezsky's disease. No. 3-5 piglets aged 3-5 weeks were diagnosed with postweaning multisystemic wasting syndrome (PMWS) and PRRSV detected by PCR. No. 9-10 piglets aged 3 months showed severe diarrhea. Others showed runting, but there is no other epidemiological information. No virus was isolated from field clinical samples, but HEV viral RNA was detected by nested PCR. In the first experiment, HEV viral RNA was detected from 10 of 32 samples by nested PCR
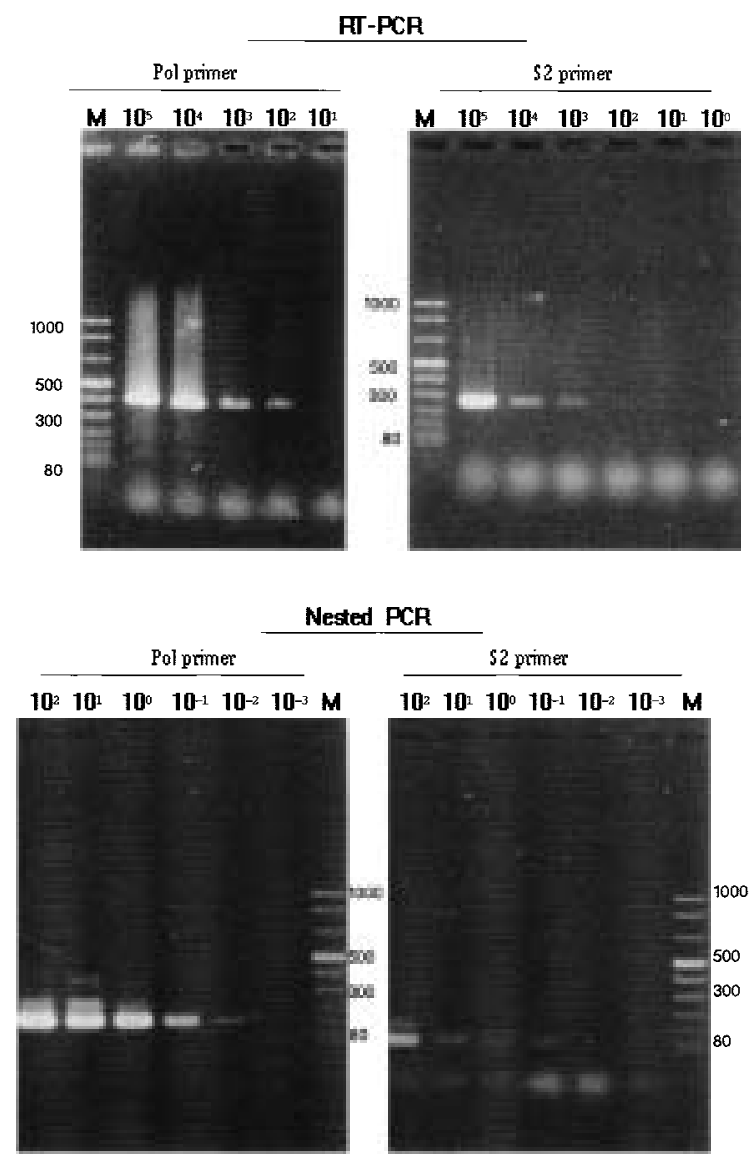

Fig. 3. Sensitivity of the RT-PCR and nested PCR to detect HEV. Products of RT-PCR were re-amplified by nested PCR, with primer sets of the Pol gene and the $\mathrm{S} 2$ gene. The $\mathrm{TCID}_{50} /$ $50 \mu l$ corresponding to the dilution is shown.

Table 1. Comparison of isolation of HEV and detection of the virus gene by RT- and nested PCR in the organ samples collected from experimentally infected mice

\begin{tabular}{ccccc}
\hline $\begin{array}{l}\text { Days after } \\
\text { inoculation }\end{array}$ & Samples & RT-PCR & $\begin{array}{c}\text { Nested } \\
\text { PCR }\end{array}$ & $\begin{array}{c}\text { Virus isolation } \\
\text { by cell culture }\end{array}$ \\
\hline \multirow{6}{*}{3 days } & brain & - & - & - \\
& kidney & - & + & - \\
& liver & - & + & - \\
& spleen & - & + & - \\
& blood & - & - & - \\
& positive control* & + & + & + \\
5 days & brain & - & + & - \\
& kidney & - & + & - \\
& liver & - & - & - \\
& spleen & - & + & - \\
& blood & - & - & - \\
\hline \multirow{6}{*}{ positive control* } & + & + & + \\
\hline
\end{tabular}

* The positive controls were prepared from the brain homogenates of HEV inoculated suckling mice. 
Table 2. Comparison of isolation of HEV and detection of the virus gene by RT- and nested PCR by using S2 primer in the samples of runting piglets

\begin{tabular}{|c|c|c|c|c|c|c|}
\hline No. of piglets & Age & Remarks & Sample & Virus isolation & RT-PCR & Nested PCR \\
\hline \multirow[t]{2}{*}{1} & $1-2$ weeks & Aujeszky's & brain & - & - & - \\
\hline & & Disease & tonsil & - & - & - \\
\hline \multirow[t]{2}{*}{2} & 1-2 weeks & Aujeszky's & brain & - & - & - \\
\hline & & Disease & tonsil & - & - & + \\
\hline \multirow[t]{2}{*}{3} & $3-5$ weeks & PMWS, PRRS & brain & - & - & - \\
\hline & & & tonsil & - & - & + \\
\hline \multirow[t]{2}{*}{4} & $3-5$ weeks & PMWS, PRRS & brain & - & - & - \\
\hline & & & tonsil & - & - & - \\
\hline \multirow[t]{2}{*}{5} & $3-5$ weeks & PMWS, PRRS & brain & - & - & - \\
\hline & & & tonsil & - & - & - \\
\hline \multirow[t]{2}{*}{6} & 1 month & runting* & brain & - & - & - \\
\hline & & & tonsil & - & - & - \\
\hline \multirow[t]{2}{*}{7} & 1 month & runting & brain & - & - & - \\
\hline & & & tonsil & - & - & - \\
\hline \multirow[t]{2}{*}{8} & 1 month & runting & brain & - & - & - \\
\hline & & & tonsil & - & - & - \\
\hline \multirow[t]{2}{*}{9} & 3 months & diarrhea & brain & - & - & - \\
\hline & & & tonsil & - & - & - \\
\hline \multirow[t]{2}{*}{10} & 3 months & diarrhea & brain & - & - & - \\
\hline & & & tonsil & - & - & - \\
\hline 11 & 1 month & runting & tonsil & - & - & - \\
\hline 12 & 1 month & runting & tonsil & - & - & - \\
\hline 13 & 1 month & runting & tonsil & - & - & - \\
\hline 14 & 2 months & runting & tonsil & - & - & - \\
\hline 15 & 2 months & runting & tonsil & - & - & - \\
\hline 16 & 2 months & runting & tonsil & - & - & - \\
\hline \multirow[t]{2}{*}{17} & 1 month & runting & brain & - & - & - \\
\hline & & & tonsil & - & - & - \\
\hline \multirow[t]{2}{*}{18} & 1 month & runting & brain & - & - & - \\
\hline & & & tonsil & - & - & - \\
\hline \multirow[t]{2}{*}{19} & 1 month & runting & brain & - & - & - \\
\hline & & & tonsil & - & - & - \\
\hline
\end{tabular}

* The piglets only recording runting had no other epidemiological data. All of the piglets showed. But a few piglets showed other symptoms.

with the Pol primer (data not shown). Therefore, we tried to confirm the specificity of HEV viral RNA from field clinical samples by PCR to test for PRRSV, which highly infects runting piglets. PRRSV was detected by RT-PCR and nested PCR with the Pol primer, but RT-PCR and nested PCR with the S2 primer did not detect PRRSV viral RNA completely. Therefore, we used the $\mathrm{S} 2$ primer instead of the Pol primer for detection in field clinical samples. As a result, HEV viral RNA was detected from 2 (tonsil samples from No. 2 and No. 3 piglets) among 32 samples by nested PCR.

\section{DISCUSSION}

Antibodies to HEV have been surveyed by using the HI test and serum neutralization test, but no method to detect the HEV gene has been used until now except for virus isolation [20]. PCR is a sensitive, specific and rapid diagnostic tool to detect pathogens of diseases. PCR can detect noninfectious pathogens [13, 14]. For example, formalin-fixed, paraffin-embedded tissue samples can be used for PCR [5]. Therefore, we tried to establish a detection method of the
HEV gene by using PCR in this study.

The complete nucleotide sequence of HEV is not yet established, but we designed the RT-PCR and nested PCR primers from sequences already established for the Pol, NS and S2 genes [23-25], but the nested PCR primer of the NS gene could not be designated, because of the sequencing of the nucleotides. These primers that we designated amplified HEV viral RNA, but not other coronavirus group 2 viruses to which HEV belongs : MHV, BCV [23], or the coronavirus group 1 virus TGEV [15]. But the Pol primer of HEV amplified PRRSV viral RNA.

HEV viral RNA was detected by PCR from experimentally infected mice samples in the brain, liver, spleen, and kidney, but not in the blood. HEV is neurotropic, like the rabies virus, and infection with the HEV virus starts in the nasal mucosa and tonsils and proceeds to the trigeminal ganglion and the trigeminal sensory nucleus in the brain stem $[8-11,26]$. HEV is transmitted from the vagal nerves to the CNS after peritoneal inoculation. In HEV infection, the viremia stage of $\mathrm{HEV}$ from this experiment is difficult to detect, although the viremia of HEV might occur a little for only a short time after the infection [2]. Therefore, we used 
brain and tonsil homogenates prepared in the experiment from piglets for field clinical samples of the PCR to detect HEV viral RNA.

HEV was detected from 10 of 32 samples of brain and tonsil homogenates of 19 piglets in the first experiment. PRRSV had highly infected the field clinical samples from runting piglets, and so we reexamined PRRSV by PCR with the Pol and S2 primers. As a result, PRRSV viral RNA was detected by the Pol primer, but the position of the bands of the RT-PCR products were different from that of HEV. PRRSV is a member of the genus Arterivirus and the family Arteriviridae [4]. The Pol gene encodes two open reading frames (ORF), 1a and 1b, and ORF 1b has highly conserved regions encoding conserved functions (e.g., polymerase and helicase activity), which, combined with similarities in replication and expression strategies, showed an evolutionary link between coronaviruses, arteriviruses and toroviruses [23]. These similarities are why these viruses are classified in the order Nidovirales. Therefore, we considered an analogy among highly conserved polymerase genes of viruses in which the PRRSV viral RNA was detected by the Pol primer of HEV. But PRRSV viral RNA was not detected by PCR with the S2 primer of HEV. RT-PCR and nested PCR with the $\mathrm{S} 2$ primer detected HEV viral RNA from 2 of 32 field samples (19 piglets). These results suggested HEV viral RNA was detectable in field clinical samples by RT-PCR and nested PCR using the S2 primer of HEV.

Large outbreaks of HEV have not been recorded in Japan, but pig farming conditions have dramatically changed recently, which increases the risk of outbreaks of HEV. These recently changed conditions are considered to be the same as pig farm conditions in countries where animal production systems are already developed. Therefore, we consider that finding the HEV infection rate of each pig farm is important. We believe that the established PCR method to detect HEV in this study can be used in further studies of HEV and shows the infectious state of HEV in modern pig farms.

\section{REFERENCES}

1. Akaike, Y. and Miyahara, T. 1985. SPF swine repopulation program. pp. 134-148. In: Pig Health Control. (Japan SPF swine association ed.), Chikusan Syuppan co, Tokyo (in Japanese).

2. Andries, K. and Pensaert, M. 1980. Virus isolation and immunofluorescence in different organs of pigs infected with hemagglutinating encephalomyelitis virus. Am. J. Vet. Res. 41: 215218.

3. Cavanagh, D. 1997. Nidovirales: a new order comprising Coronaviridae and Arteriviridae. Arch. Virol. 142/3: 629-633.

4. Den Boon, J.A., Snijder, E.J., Chirnside, E.D., DeVries, A.A.F., Horzinek, M.C. and Spaan, W.J.M. 1991. Equine arteritis virus is not a togavirus but belongs to the coronavirus superfamily. J. Virol. 65: 2910-2920.

5. Hasegawa, M., Shioya, H., Yuyama, Y., Otani, T., Kamio, Y., Maruyama, T. and Tsujioka, T. 2001. Pigs confirmed to be infected with porcine circovirus 2 as early as 1988. J. Jpn. Vet. Med. Assoc. 54: 757-760 (in Japanese with English summary).
6. Hirahara, T., Yasuhara, H., Kodama, K., Nakai, M. and Sasaki, N. 1987. Isolation of hemagglutinating encephalomyelitis virus from respiratory tract of pigs in Japan. Jpn. J. Vet. Sci. 49: 85-93.

7. Hirai, K., Chang, C. and Shimakura, S. 1974. A Serological survey on hemagglutinating encephalomyelitis virus infection in pigs in Japan. Jpn. J. Vet. Sci. 36: 375-380.

8. Hirano, M., Haga, S. and Fujiwara, K. 1993. The route of transmission of hemagglutinating encephalomyelitis virus (HEV) $67 \mathrm{~N}$ strain in 4-week old rats. Adv. Exp. Med. Biol. 342: 333338.

9. Hirano, N., Haga, S., Sada, Y. and Tohyama, K. 2001. Susceptibility of rats of different ages to inoculation with hemagglutinating encephalomyelitis virus (a coronavirus) by various routes. J. Comp. Pathol. 125: 8-14.

10. Hirano, N., Nomura, R., Tawara, T., Ono, K. and Iwasaki, Y. 1995. Neuronal spread of hemagglutinating encephalomyelitis virus (HEV) $67 \mathrm{~N}$ strain in 4-week old rats. Adv. Exp. Med. Biol. 380: 117-119.

11. Hirano, N., Tohyama, K. and Taira, H. 1998. Spread of swine hemagglutinating encephalomyelitis virus from peripheral nerves to the CNS. Adv. Exp. Med. Biol. 440: 601-607.

12. Honda, E., Takahashi, H., Okazaki, K., Minetoma, T. and Kumagai, T. 1990. The multiplication of transmissible gastroenteritis virus in several cell lines originated from porcine kidney and effects of trypsin on the growth of the viruses. Jpn. J. Vet. Sci. 52: 217-224.

13. Kim, L., Chang, K.O., Sestak, K., Parwani, A. and Saif, L.J. 2000. Development of a reverse transcription-nested polymerase chain reaction assay for differential diagnosis of transmissible gastroenteritis virus and porcine respiratory coronavirus from feces and nasal swabs of infected pigs. J. Vet. Diagn. Invest. 12: 385-388.

14. Kono, Y., Kanno, T., Shimizu, M., Yamada, S., Ohashi, S., Nakamine, M. and Shirai, J. 1996. Nested PCR for detection and typing of porcine reproductive and respiratory syndrome (PRRS) virus in pigs. J. Vet. Med. Sci. 58: 941-946.

15. Lai, M. and Cavanagh, D. 1997. The molecular biology of coronaviruses. Advances in Virus Res. 48: 1-102.

16. Makino, S., Taguchi, F. and Fujiwara, K. 1984. Defective interfering particles of mouse hepatitis virus. Virology 133: 917.

17. Mebus, C.A., Stair, E.L., Rhodes, M.B. and Twiehaus, M.J. 1973. Neonatal calf diarrhea propagation, attenuation and characteristics of a coronavirus-like agent. Am. J. Vet. Res. 34: 145-150.

18. Mengeling, W.L., Boothe, A.D. and Ritchie, A.E. 1972. Characteristics of a coronavirus (strain $67 \mathrm{~N}$ ) of pigs. Am. J. Vet. Res. 33: 297-308.

19. Murakami, Y., Kato, A., Tsuda, T., Morozumi, T. and Sugimura, T. 1994. Isolation and serological characterization of porcine reproductive and respiratory syndrome (PRRS) viruses from pigs with reproductive and respiratory disorders in Japan. J. Vet. Med. Sci. 56: 891-894.

20. Pensaert, M.B. 1999. Hemagglutinating Encephalomyelitis. pp. 151-157. In: Diseases of Swine, 8th ed. (Straw, B.E., D'Allaire S., Mengeling,W.L. and Taylor D.J. eds.), Iowa University Press, Ames.

21. Sakoda, Y. and Fukusho, A. 1998. Establishment and characterization of a porcine kidney cell line, FS-L3, which forms unique multicellular domes in serum-free culture. Dev. Biol. Anim. 34: 53-57.

22. Sato, K., Inaba, Y. and Matumoto, M. 1980. Serological rela- 
tionship between calf diarrhea coronavirus and hemagglutinating encephalomyelitis virus. Arch. Virol. 66: 157-159.

23. Stephansen, C.B., Casebolt, D.B. and Gangopadhyay, N.N. 1999. Phylogenetic analysis of a highly conserved region of the polymerase gene from 11 coronaviruses and development of a consensus polymerase chain reaction assay. Virus Res. 60: 181-191.

24. Vieler, E., Schlapp, T., Anders, C. and Herbst, W. 1995. Genomic relationship of porcine hemagglutinating encephalomyelitis virus to bovine coronavirus and human coronavirus
OC43 as studied by the use of bovine coronavirus $\mathrm{S}$ gene-specific probes. Arch. Virol. 66: 157-159.

25. Vieler, E., Schlapp, T. and Herbst, W. 1996. The region between the $\mathrm{M}$ and $\mathrm{S}$ genes of porcine haemagglutinating encephalomyelitis virus is highly similar to human coronavirus OC43. J. Gen. Virol. 77: 1443-1447.

26. Yagami, K., Hirai, K. and Hirano, N. 1986. Pathogenesis of hemagglutinating encephalomyelitis virus (HEV) in mice experimentally infected by different routes. J. Comp. Pathol. 96: $21-27$. 